\title{
In Nepal, a woman's reproductive system is her greatest vulnerability
}

Published at www.cmaj.ca on July 28

$\mathrm{T}$ he woman lies on an examining table of cracked leather and rusted metal. Her legs - squat and muscled from carrying $20-\mathrm{kg}$ loads of water up and down mountains - are swollen. Her hair escapes its clip in teased-out loops. She seems delirious after spending the day in labour, first at home, then at a smaller government centre and now here, at Bayalpata Hospital in Achham district of western Nepal.

Under five feet, the woman is considered high-risk because of her small stature. But as Dan Schwarz, the executive director of the NGO that runs the hospital, points out, "referring her to a facility that can do a cesarean means putting her on the road for six hours to the nearest hospital at high speeds, with a single driver, at night."

Four hours later the baby arrives, but she is not making any movements. For the next hour, Schwarz rhythmically squeezes an air pocket of a machine that breathes on the little girl's behalf. By the time the on-call staff leaves, the child is making crackly gurgles.

If the woman hadn't come to the hospital, she may not have survived labour. Still, more than $95 \%$ of pregnant Accham women give birth at home, says Schwarz. The biggest challenge to addressing Nepal's maternal mortality - 281 in 100000 live births, according to the 2006 Democratic and Health Survey - is getting women to come to the hospital in the first place.

Service fees, transportation costs and the time involved in getting to a hospital are the main reasons so many women labour at home. The government is trying to address these barriers with a new program that offers free service and incentives, but other challenges to combating maternal mortality remain. Remote hospitals are underequipped and understaffed, and the dis-

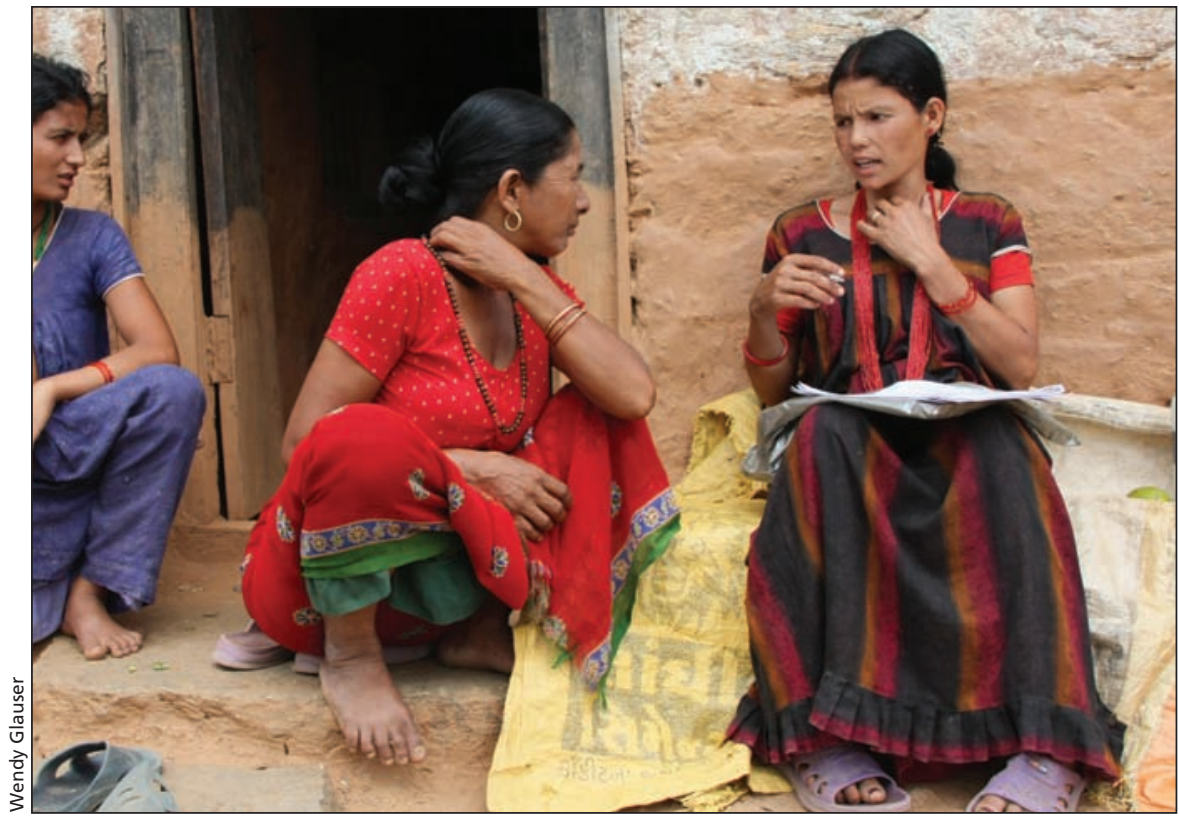

A community health worker interviews women in a remote village in Nepal about their knowledge of hospital services and the incentive program created to encourage pregnant women to give birth in hospitals.

empowerment of young women makes it difficult for them to take control of health decisions.

In 2005, the government launched a program that pays women to deliver in hospitals, and last year the "Aama" initiative expanded the incentive program to ensure that delivery services and medicines are provided free at government hospitals.

Women giving birth in the high Himalayas receive about $\$ 21$; those who deliver in the middle hilly region are awarded \$14; and in the flat Terai region, the payout is $\$ 7$. While far from scientific, the fee system takes into account that women living in the country's mountainous region must travel, on average, eight hours to the nearest hospital, while in the hilly areas, travel time is about six hours, and in the Terai, just over two.

The initial incentive program came on the heels of a 2004 survey of 720 households conducted by Nepal's Min- istry of Health and the UK's Department for International Development (DFID). The survey revealed that the informal costs of delivering in a hospital were often more burdensome than the user fees in place at the time.

"Someone has to go with you," explains Greg Whiteside, a team leader for the Support to the Safe Motherhood Programme (SSMP), a DFID initiative that provides technical support and funding to Nepal's government. In addition to the opportunity cost in lost labour for a travel companion, travel costs can be staggering in remote, mountainous areas. "You often need porters to carry you," says Whiteside, a service that puts households out $\$ 40$, on average.

Since the incentive program was put into place, the proportion of deliveries taking place in health facilities has increased from $27 \%$ to $47 \%$. The waiving of hospital fees is also proving to change behaviour, especially among the more marginalized, according to 
ministry monitoring and evaluation data released in June. For Dalits, considered the untouchable caste, health facility deliveries have gone up $20 \%$ since the availability of free services, while among the higher Newar caste, the increase was only $7 \%$.

Still, chatter among postdelivery women at Kathmandu's Maternity Hospital, a government facility, reveals that factors more complicated than cost make a woman's reproductive system her greatest vulnerability.

"I was happy with my girls, but I was getting a lot of pressure from my family to have a boy," says Bimala, 31, who has 11- and 14-year-old daughters, while sitting on a hospital bed beside a newborn boy.

Eighteen-year-old Lila, meanwhile, says she didn't even realize she was pregnant until she was seven months along. "At around three to four months I went to the clinic because I was vom- iting a lot, but they didn't tell me I was pregnant." For women in Nepal, the social role to help others means they're unlikely to help themselves by seeking out services and information.

Because they're often destined, by tradition, to take care of their in-laws, Nepali girls tend to be less valued by their birth parents. Young women are rarely educated beyond secondary school and do the majority of domestic and field work, often under "the harsh regime of the mother-in-law," as Whiteside describes it. Abortion, often utilized as a sex-selection tool, is the third leading cause of maternal mortality in Nepal, after hemorrhaging and eclampsia.

Back at the remote hospital in Accham, the baby, now two days old, lies lifeless beside her mother, who stares at the wall with tear-filled eyes and doesn't speak to anyone. Her firstborn didn't even make it to her naming ceremony.
The death of the baby girl and the revelations of postdelivery mothers at Kathmandu's maternity hospital show that, while the Aama program is helping, cash rewards only go so far.

"If she had of come in for antenatal visits, we would have been able to measure the head and schedule her for a cesarean," says Dr. Sona Shilpakar, who works at Bayalpata.

So many of the reasons women and babies die - low levels of education, daily power outages and incredibly cash-strapped hospitals, to name a few - are challenges that won't go away with a stipend.

"Sometimes I just want to go into a room and cry," says Urmila Basnet, a nurse midwife at Bayalpata Hospital, as she looks over to the woman who has lost her baby. "Sometimes I do." Wendy Glauser, Achham, Nepal

DOI:10.1503/cmaj.109-3316 